\title{
Expression of Ki67 Biomarker in Oral Submucous Fibrosis with Clinico-Pathological Correlations: A Prospective Study
}

\author{
KA Kamala ${ }^{1 *}$, Sujata R Kanetkar ${ }^{2}$, Kailash D Datkhile ${ }^{3}$, S Sankethguddad ${ }^{4}$
}

\begin{abstract}
Objectives: Oral Submucous Fibrosis (OSMF) is potentially malignant disorder known to transform into oral cancer. The aim of this study is to determine the degree and pattern of expression of aberrant Ki67 in OSMF, oral squamous cell carcinoma (OSCC) and in normal oral mucosa patients (NOM). The objective is to correlate between Ki67 expression and degree of dysplasia in OSMF patents and also Ki67 expression with clinical and histological grading of OSMF and OSCC patient. Materials and Methods: A prospective cross-sectional study was conducted with purposive sampling technique from Jan 2017 to April 2020.The study groups consist of 35 OSMF cases, 10 cases of each OSCC and NOM. The samples were immunohistochemically analyzed for expression Ki67 antigen using chi-square test $(\mathrm{P}<0.05)$. Results: The expression of Ki67 was significantly higher in OSMF than that of NOM samples, but less than that of OSCC samples. Present study showed correlation between expression of Ki67 with clinical staging and histological grading both in OSMF and OSCC patients. Conclusion: The study demonstrated a high incidence of Ki67 over expression in, OSMF and OSCC. Hence, Ki-67 can be widely used as a proliferation marker to measure growth fraction of cells in OSMF and also for determining the severity of epithelial dysplasia.
\end{abstract}

Keywords: Oral submucous fibrosis- malignant transformation- Ki67 biomarkers- immunohistochemistry

Asian Pac J Cancer Prev, 23 (1), 253-259

\section{Introduction}

Oral Submucous Fibrosis (OSMF) is a potentially malignant disorder (PMD) of the oral cavity seen predominately in the Indian subcontinent and South East Asia (Wollina et al., 2015). Southeast Asia where Oral cancer is a major public health problem, over $90 \%$ of oral malignancies are known to arise from preexisting potentially malignant lesions and conditions (Sultana et al., 2011).

Many recent epidemiological studies show that there is marked increase in the prevalence of OSMF (Manjunath et al., 2019; Nigam et al., 2014). Previous data and intervention studies suggest that areca nut is the main etiological factor for OSMF and is the fourth most commonly used psychoactive substance in the world (following nicotine, ethanol and caffeine) (Shrikrishna et al.,2016; Narang et al., 2017; Yang et al., 2018). One of the important hallmarks of malignant transformation (MT) is the uncontrolled growth rate, commonly reflected as increased cell proliferation (Humayun et al., 2011). High proliferative activity and basal cell hyperplasia in conjunction with rapid exfoliation of superficial cells and epithelial atrophy suggest that epithelial turnover rate is very high in OSMF (Reddy et al., 2016).

The proliferative activity of any tissue or neoplasm can be determined by its growth rate using antibodies directed against specific antigens expressed by proliferating neoplastic cells, allowing the simultaneous analysis of cell proliferation and histology (Vieira et al., 2008).

$\mathrm{Ki} 67$ is a proliferative marker, identified at the University of Kiel, Germany. The expression of Ki67 occurs in all phases of the cell cycle except G0 phase and early G1 phase. It increases in S phase which correlates with the growth fraction and is indicative of the proliferative capacity of the cell, making it an excellent proliferative marker (Dwivedi et al., 2013).

Although the significant roles played by oncogenes and tumor suppressor genes in the development of OSCC have been explored till date, there are few data on proliferative markers like Ki67 in OSMF and also its value in diagnosis and prognostic evaluation of precancerous lesions and conditions. Ki67 is considered as the most suitable biological marker of mitotic activity due to its nuclear expression during a defined period of the cell cycle (Iqbal et al 2020).

${ }^{1}$ Department of Oral Medicine and Radiology. School of Dental Sciences, KIMSDU, Karad, Pin code -415110, District- Satara, Maharashtra, India. ${ }^{2}$ Department of Pathology, Krishna Institute of Medical Sciences, Karad, Pin code -415110, DistrictSatara, Maharashtra, India. ${ }^{3}$ Department of Molecular Biology and Genetics, Krishna Institute of Medical Sciences, Karad. Pin code -415110, District- Satara, Maharashtra, India. ${ }^{4}$ Consultant Periodontist and Implantologist, Karad, Maharashtra, India. *For Correspondence: kamsweetsmile@gmail.com 
This study aims i) to determine the degree and pattern expression of aberrant $\mathrm{Ki} 67$ in OSMF, OSCC and in normal oral mucosal patients (NOM) ii) to correlate between Ki67 expression and degree of dysplasia in OSMF patents iii) to correlate Ki67 expression with clinical and histological grading of OSMF and OSCC patient and to show Ki67 antigens surrogatebiomarker useful in detecting high-risk OSMF patients for MT.

\section{Materials and Methods}

\section{Study Design, and Participants}

This prospective cross-sectional observational study was conducted in department of Oral Medicine and radiology, School of Dental sciences KIMSDU, Karad, Satara, Maharashtra from Jan 2017 to April 2020. The patients were drawn from outpatient department (OPD) of Oral Medicine and radiology using purposive/subjective sampling technique. Ethical Clearance from institutional ethical committee and the written informed consent (in local language Marathi) from all patients were obtained before the start of the study.

\section{Samples Size}

Thirty five cases of OSMF who were having habit of chewing arecanut in processed forms and others, and 10 cases of OSCC patients with habits of tobacco and other products, and 10 cases of NOM without any habit and OSMF were considered for the study. Normal tissues were obtained from the buccal mucosa of 10 patients during the surgical removal of the third molar which served as negative controls and OSCC patients as positive controls.

The inclusion criteria of the study were individuals with clinically diagnosed as OSMF and OSCC with habits. The exclusion criteria were medically compromised patients and the patients who did not gave the written informed consent. Demographic details were recorded for all the patients. Diagnosis of OSMF and OSCC were made on the basis of characteristic clinical features (Shih et al., 2019; Carreras-Torras et al., 2015). All the patients were subjected to incisional biopsy and clinical diagnosis was confirmed by histopathologically. The clinical staging and histological grading of OSMF and OSCC were done according to Utsunomiya $\mathrm{H}$ et al., (2005) and Akhter M et al., (2011) and classification of Epithelial dysplasia was done according to Warnakulasuriya $\mathrm{V}$ et al., (2008)

- There were no bias in the selection samples observed and no drop of the study was noted.

All the biopsied tissues specimens were fixed in 10\% neutral buffered formalin for 24- 48 hours and embedded in paraffin wax using standard procedures. The biopsied tissues were cut into $3 \mu \mathrm{m}$ thickness of tissue sections and Haematoxylinand Eosin (Loba Chemie Pvt. Ltd, Mumbai, India) staining was done for histopathological diagnosis for all cases. Additional sequential sections were prepared for immunohistochemical (IHC) study.

\section{Immunohistochemistry protocol}

All 35 cases of OSMF were available for high-quality IHC staining. The sections on frosted slides were deparafinized in xylene for 3 times 5 minutes each thereafter rehydrated in different concentrations of ethanol (Dako Denmark).

The antigen retrieval was carried out in Envision FLEX target retrieval solution, high pH (Dako; K8004) containing Tris-EDTA buffer $\mathrm{pH} 9$ for 30 minutes in autoclave. After washing with distilled water at $25^{\circ} \mathrm{C}$, the slides were incubated with Envision FLEX wash buffer containing Tris buffered saline solution with Tween 20 pH:7.6 (Dako: K8007) for 20 minutes followed by blocking with Envision FLEX peroxidase blocking reagent (Dako, Denmark) containing phosphate buffer with $15 \mathrm{mmol} /$ Litre hydrogen peroxide, sodium azide and detergent (Dako: SM801). After 20 minutes $\mathrm{H}_{2} \mathrm{O}_{2}$ blocking, the sections were incubated directly with primary antibodies, Ki67 antigen clone MIB-1, ready to use (DakoAutostrainer/Autostrainerplus, Dako Denmark A/S Produktionsvej 42 DK-2600 Glostrup, Denmark), for 1 hour at room temperature in humidity chamber.

Thereafter, the sections are washed with wash buffer for 5 minutes followed by treatment with Envision FLEX/HRP goat secondary antibody against rabbit and mouse immunoglobulins coupled with peroxidase molecules (Dako: SM802). After completion of 1 hour incubation with secondary antibody, sections were washed with distilled water for 5 minutes. The sections were stained with Envision FLEX DAB + Chromogen (3, 3' diaminobenzidine tetra hydrochloride) (Dako: DM827) in Envision FLEX substrate buffer containing hydrogen peroxide and preservative (Dako: SM803) till the brownish red color development. The sections were counter stained with hematoxylinfor 2-3 minutes after washing with distilled water. After drying the slides, slides were dipped into $100 \%$ ethanol and thereafter xylene for clearing the sections. The slides were mounted in DPX mountant and observed under Primovert Phase contrast microscope (Carl Zeiss).

\section{Scoring system}

All images were captured under 10x and 20x magnification. Immunostained sections for p53 was independently examined in detail by pathologists, and the expression of $\mathrm{p} 53$ protein was carried out based on intensity of staining. For antibodies staining the nuclei the labeling index (LI) was calculated, for this purpose 100 cells were counted and LI were calculated as follows:

$$
\mathrm{LI}=\frac{\text { Number of positive cells }}{\text { Number of cells }} \times 100
$$

The protein expression was scored as follows (Bathi et al., 2003).

1. (-) negative when $<5 \%$ of cells staining positive.

2. (+) low when $5 \%-50 \%$ of cells staining positive.

3. (++) intermediate when $50 \%-75 \%$ of cells staining positive.

4. $(+++)$ high when greater than $75 \%$ of cells staining positive were considered.

\section{Statistical analysis}

Data were entered and analyzed using Statistical 
Package for the Social Sciences version 21 (SPSS 21, IBM Corporation, United States). The chi-squared test was used to analyze the differences between the intensity levels, in NOM, OSMF, and OSCC. Fisher's exact test was applied to compare the biomarkers determining between the absence and presence of epithelial dysplasia and between cancerous transformation and non-transformation OSMF. Differences with a probability value of $\leq 0.05$ were considered statistically significant.

\section{Results}

Expression of Ki67 in OSMF, Oral Carcinoma and Normal patients

A total of 35 cases of OSMF and 10 cases of each OSCC and NOMwere studied for the expression of Ki67 oncoprotein. All the $35(100 \%)$ cases of OSMF showed expression of Ki67 in that 12 (34.2\%) showed intermediate $(50-75 \%$ cells positive stain) expression and rest $23(65.7 \%)$ showed high ( $>75-100$ cells positive stain) expression of Ki67. Out of 10 OSCC cases, 1 $(10 \%)$ case showed intermediate $(50-75$ positive stained cells) expression, and rest $9(90 \%)$ showed high (>75100 positive stained cells) expression of Ki67. Out of 10 control (NOM) cases, 1 (10\%) cases showed very low + expression and rest 9 (90\%) cases showed negative expression of Ki67. Expression of Ki67 in OSMF (Figure 1), OSCC (Figure 2) and in normal patients showed statistically significant (Table 1).

\section{Clinico-pathological characteristic and risk of malignant transformation}

The medium follow-up period for the patient

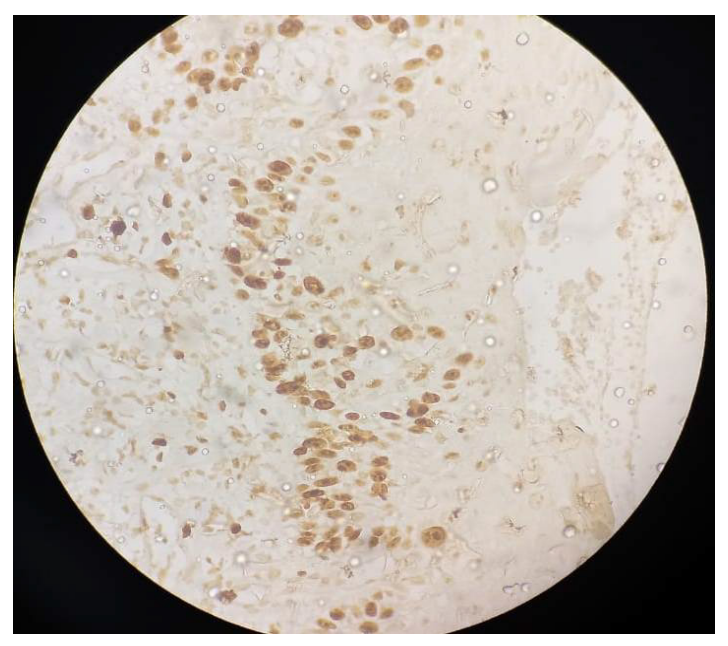

Figure 1. Expression of Ki67 in OSMF 40X population was 3.5 years, with $8(22.58 \%)$ of 35 patients transformed to invasive carcinoma. The clinicopathological characteristic didn't show any correlation with Ki 67 expression (Table 2).

\section{Expression of Ki67 and degree of dysplasia in OSMF patients}

Out 22 epithelial dysplasia cases $1(4.54 \%)$ case showed negative Ki67 expression,4 (18.18\%) cases showed low (5-50 cells), 7 (31.81\%) cases showed intermediate (50-75cells) and $10(45.45 \%)$ cases showed high (>75 cells) expression of Ki67. On application of Chi-Square test, a statistically significant $\mathrm{p} \leq 0.05$ i.e 0.0032 was obtained, which showed there is association between Ki67 expression and epithelial dysplasia (Table 3 and Figure 3 ) .

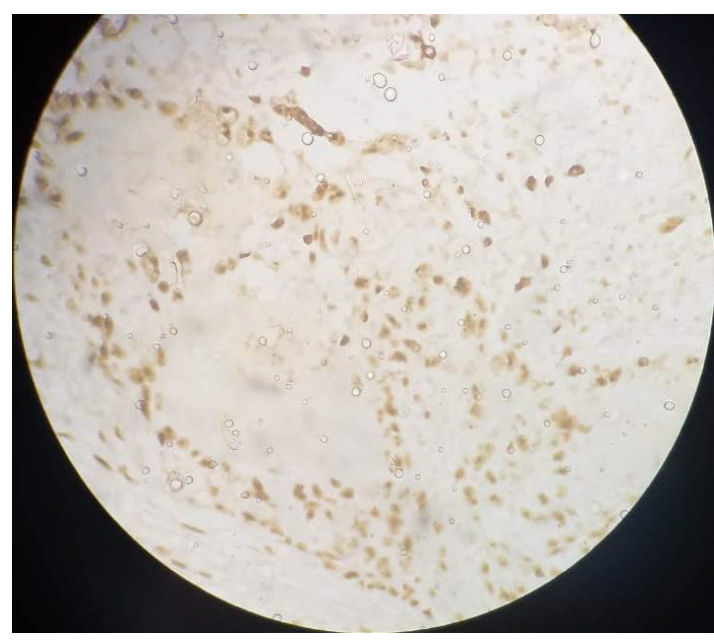

Figure 2. Expression of KI67 in OSCC 40X

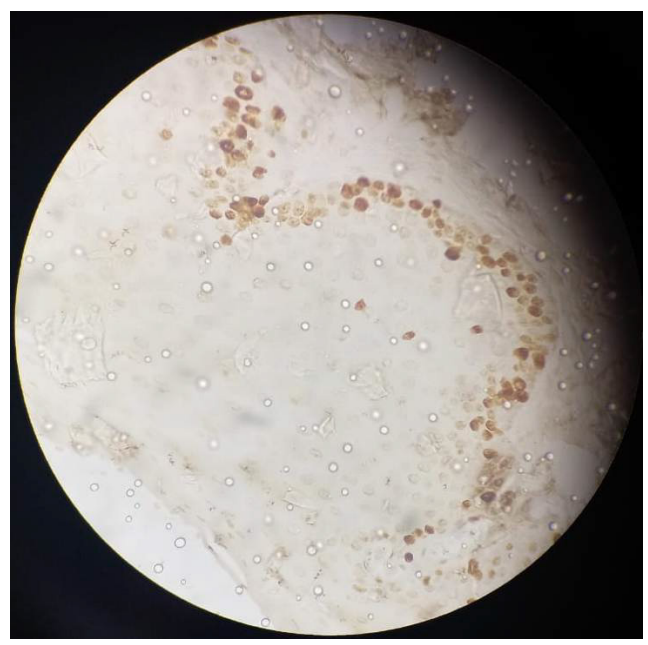

Figure 3. Expression of Ki67 in Dysplasia

Table 1. Expression of Ki67 in OSMF, OSCC, Normal Patients (Bathi et al ., 2003)

\begin{tabular}{lccccc}
\hline Expression of Ki67 & OSMF N=35 (\%) & OSCC N=10 (\%) & Normal N=10 (\%) & Chi- square test & $(\mathrm{p}$-value $)$ \\
\hline Negative & $0(0)$ & $0(0)$ & $9(90)$ & 45.05 & $<0.0001^{*}$ \\
Low $(+)$ & $0(0)$ & $0(0)$ & $1(1)$ & $\mathrm{df}=6$ & \\
Intermediate $(++)$ & $12(34.2)$ & $1(10)$ & $0(0)$ & & \\
High $(+++)$ & $23(65.7)$ & $9(90)$ & $0(0)$ & & \\
Total & $35(100)$ & $10(100)$ & $10(100)$ & & \\
\hline
\end{tabular}

*Significant when $\mathrm{p} \leq 0.05 ; \mathrm{df}$, degrees of freedom 
Table 2. Clinico-pathological Characteristic of OSMF

\begin{tabular}{|c|c|c|c|c|}
\hline Parameters & $\begin{array}{c}\text { No of OSMF patients } \\
(\%) \mathrm{N}=35\end{array}$ & $\begin{array}{l}\text { Without Malignant } \\
\text { Transformation (\%) }\end{array}$ & $\begin{array}{c}\text { With Malignant } \\
\text { Transformation (\%) }\end{array}$ & p-value \\
\hline \multicolumn{5}{|l|}{ Gender } \\
\hline Female & $6(17.14)$ & $4(14.81)$ & $2(25)$ & $0.60(\mathrm{NS}) \mathrm{df}=2$ \\
\hline Male & $29(82.85)$ & $23(85.18)$ & $6(75)$ & \\
\hline \multicolumn{5}{|l|}{ Age } \\
\hline$<45$ & $26(74.28)$ & $20(74.07)$ & $6(75)$ & $1.0(\mathrm{NS})$ \\
\hline$\geq 45$ & $9(25.71)$ & $7(25.91)$ & $2(25)$ & $\mathrm{df}=2$ \\
\hline \multicolumn{5}{|c|}{ Site of malignant changes } \\
\hline Buccal mucosa & $30(85.74)$ & $23(85.18)$ & $7(87.5)$ & $0.86(\mathrm{NS}) \mathrm{df}=4$ \\
\hline Tongue & $1(2.85)$ & $1(3.70)$ & $0(0)$ & \\
\hline Soft palate & $4(11.42)$ & $3(11.11)$ & $1(12.5)$ & \\
\hline \multicolumn{5}{|l|}{ Presence of Dysplasia } \\
\hline With Dysplasia & $22(62.85)$ & $26(74.28)$ & $8(100)$ & $0.17(\mathrm{NS}) \mathrm{df}=2$ \\
\hline Without Dysplasia & $13(37.41)$ & $9(25.71)$ & $0(0)$ & \\
\hline
\end{tabular}

*Significant when $\mathrm{p} \leq 0.05 ; \mathrm{df}$, degrees of freedom

Table 3. Expression of Ki67 and Degree of Dysplasia in OSMF Patients (Warnakulasuriya et al., 2008)

\begin{tabular}{lccccccc}
\hline $\begin{array}{l}\text { Degree of } \\
\text { dysplasia }\end{array}$ & Negative (-) \% & Low $\%(+) \%$ & Intermediate $(++) \%$ & High $(+++) \%$ & Total \% & $\begin{array}{c}\text { Chi- square } \\
\text { test }\end{array}$ & p-value \\
\hline Negative & $1(4.54)$ & $0(0)$ & $0(0)$ & $0(0)$ & $1(4.54)$ & $24.84 \mathrm{df}=9$ & $0.0032 *$ \\
Mild & $0(0)$ & $1(4.54)$ & $2(9.09)$ & $1(4.54)$ & $4(18.18)$ & & \\
Moderate & $0(0)$ & $1(4.54)$ & $2(9.09)$ & $1(4.54)$ & $4(18.18)$ & & \\
Severe & $0(0)$ & $2(9.09)$ & $3(13.63)$ & $8(36.36)$ & $13(59.09)$ & & \\
Total & $1(4.54)$ & $4(18.18)$ & $7(31.81)$ & $10(45.45)$ & $22(100)$ & & \\
\hline
\end{tabular}

*Significant when $\mathrm{p} \leq 0.05$; df, degrees of freedom

Correlation of Ki76 expression with clinical and histological staging of OSMF and histological grading of OSCC

In clinical staging of OSMF out of 35 cases, 4 $(11.42 \%)$ were early, $20(57.14 \%)$ were in moderate and $11(31.42 \%)$ were in advanced clinical staging. When the expression of Ki67 was compared 10(28.57\%) were in moderate and $25(71.42 \%)$ were in advanced staging. In histological grading of OSMF $7(20 \%)$ were in early, $19(54.28 \%)$ were in moderate and $9(25.71 \%)$ were in advanced grading. When the expression of Ki67 was compared, 7 (20\%) were in moderate and 28
$(80 \%)$ were in advanced grading (Table 4). Histological grading of OSCC $14(40 \%)$ and $21(60 \%)$ cases were in moderate and poorly differentiated respectively. When expression of Ki67 was compared 2 (5.71\%) were in well, $22(62.85 \%)$ were in moderate and $11(31.42 \%)$ were in poorly differentiated grades respectively (Table 5). On application of chi-square test, there was correlation (statistically significant $\mathrm{p} \leq 0.05$ ) between expression of Ki67 with clinical and histological staging of OSMF and with histological grading of OSCC.

Table4.Correlation ofKi67Expression with Clinical andHistologicalGrading ofOSMF Patients(Utsunomiyaetal.,2005)

\begin{tabular}{|c|c|c|c|c|}
\hline Parameters & OSMF patients $(\%)$ & Expression of Ki76 (\%) & Chi- square test & p-value \\
\hline \multicolumn{5}{|l|}{ Clinical staging } \\
\hline Early Cases & $4(11.42)$ & 0 & $12.78 \mathrm{df}=2$ & $0.0017^{*}$ \\
\hline Moderately advanced cases & $20(57.14)$ & $10(28.57)$ & & \\
\hline Advanced cases & $11(31.42)$ & $25(71.42)$ & & \\
\hline Total & $35(100)$ & $35(100)$ & & \\
\hline \multicolumn{5}{|l|}{ Histological grading } \\
\hline Early Cases & $7(20)$ & 0 & $22.3 \mathrm{df}=2$ & $<0.0001^{*}$ \\
\hline Moderately advanced cases & $19(54.28)$ & $7(20)$ & & \\
\hline Advanced cases & $9(25.71)$ & $28(80)$ & & \\
\hline Total & $35(100)$ & $35(100)$ & & \\
\hline
\end{tabular}

*Significant when $\mathrm{p} \leq 0.05$; df, degrees of freedom 
Table 5. Correlation of Ki 67 Expression with Histological Grading of OSCC (Akhteret al., 2011)

\begin{tabular}{lcccc}
\hline Clinical grading & OSCC patients & Expression of Ki67 & Chi- square test & p-value \\
\hline Well differentiation & $0(0)$ & $2(5.71)$ & $6.903, \mathrm{df}=2$ & $0.0317^{*}$ \\
Moderately differentiated & $14(40)$ & $22(62.85)$ & & \\
Poorly differentiated & $21(60)$ & $11(31.42)$ & & \\
Total & $35(100)$ & $35(100)$ & & \\
\hline
\end{tabular}

*Significant when $\mathrm{p} \leq 0.05$; df, degrees of freedom

\section{Discussion}

The data for Ki67 in OSMF are very much limited, especially in India. In the present study all $35(100 \%)$ cases of OSMF showed expression of $\mathrm{Ki} 67$, in that $12(34.2 \%)$ showed intermediate $(++)$ and $23(65.7 \%)$ showed high $(+++)$ expression. In SCC $1(10 \%)$ cases showed intermediate and rest $9(90 \%)$ cases showed high expression. In normal patients $9(90 \%)$ cases showed negative and $1(10 \%)$ case showed low expression. The pattern of Ki67 expression was statistically significant $(\mathrm{p} \leq 0.05)$.

Similar percentage $(100 \%)$ was observed in a study by Patel et al., (2014). Raju et al., (2005) observed Ki-67 expression in $93.10 \%$ of premalignant lesion and $90 \%$ of oral cancer. Dragomir et al., (2012) in their study observed that all cases of Oral SCC expressed Ki-67. Motta et al., (2009) showed 92.75\% cases with Ki-67 expression. Ranganathan and Kavitha (2011) assessed the expression of p53, Ki67, Bcl2, Bax in normal epithelium, OSMF, and SCC by IHC technique. The LI of Ki67 in OSMF patients was significantly higher than that of normal but less than that of OSCC. The authors concluded that they can be used as surrogate markers of MT.

The present study did not show any correlation with clinicopathologic variables. However of 35 cases 22 (62.85) showed epithelial dysplasia and out of 22 epithelial dysplasia cases 8 cases showed MT. Similar results were observed by Bazarsad et al., (2017) and Bhayekar et al., (2016) where the authors did not correlate the expression of Ki 67 with clinipathological variables.

Recent epidemiological data indicate that the prevalence of OSMF has increased since 2000 from 2.42 in 2000 to $6.42 / 1000 /$ year in 2004 (Hazarey et al., 2007). One study recognized that OSCC originating from OSMF is clinically more invasive and also exhibits a higher metastasis and recurrence rate than OSCC not originating from OSMF (Nair et al., 2004). Therefore, there has been much focus on investigating biomarkers for the prevention and early detection of its MT.

Present study showed positive correlation between expression of $\mathrm{Ki} 67$ and epithelial dysplasia. As the degree of epithelial dysplasia increased the expression of Ki67 also increased suggesting the high risk of OSMF patents to MT. Jayasinghe et al., (2015) and Hsue et al., (2007) stated that one of the most important predictors of MT of OSMF is the presence of epithelial dysplasia at the initial biopsy. It has been reported that $\mathrm{Ki} 67$ is overexpressed in the suprabasal epithelium, increasing with the severity of Dysplasia (2018).

In contrast to our study Bazarsad et al., (2017) could not find the positive correlation between epithelial dysplasia and MT in OSMF. This discrepancy can be explained by insufficient number of the study samples and the subjectivity of determining epithelial dysplasia.

Few authors Dwivedi et al., (2013); Dash et al., (2010); and Takkem et al., (2018) studied degree of epithelial dysplasia depending of epithelial layers. They suggested that in NOM expression of Ki67 was limited only basal layer, where as in oral epithelial dysplasia and OSCC expression was seen in basal, suprabasal and spinous layer. There was an increase in the expression of Ki-67 with the severity of dysplasia. The authors concluded thatKi-67 antigen could be used as a marker for the histological grading of epithelial dysplasia and OSCC and it provides objective criteria for determining the severity of epithelial dysplasia.

Our study showed the correlation between Ki76 expression with clinical and histological staging of OSMF and histological grading of OSCC which was statistically significant. Similar observation was shown by Iqbal et al., (2020) where the author correlated Ki67 expression with functional grading and epithelial thickness in OSMF. Author concluded that as the functional staging increased, the Ki67 expression also increased in OSMF patients. Ki67 expression was highest in severe functional staging/severely decreased mouth opening and is least in mild functional staging/mild decreased mouth opening. However, there was no significant correlation between epithelial thickness and functional staging/mouth opening.

Verma et al., (2014) compared the mean Ki-67 expression between normal and OSCC patients. Expression of Ki67 was higher in OSCC patients compared to normal. The Ki-67 expression was linearly increased from normal mucosa through various grades of OSCC which was significant difference $(\mathrm{P}<0.001)$.

In conclusion, the limitation of the present study was less sample size and lack of 1:1 ratio, because only 10 cases of each OSCC and NOM patients were considered for the study. The present study showed there was increase in the expression of Ki67 antigen from NOM to OSMF and OSCC patients. Further there was an increase in the expression of Ki-67 with the severity of dysplasia. Identification of high risk patients in OSMF with MT, early intervention and preventive measures can be incorporated in treatment modality to reducing the mortality, morbidity and cost of treatment associated with MT of OSMF.Hence, Ki-67 can be widely used as a proliferation marker to measure growth fraction of cells in OSMF and also for determining the severity of epithelial dysplasia.However,more studies, with large study samples, long-term follow-ups and use of other 
proliferative markers would further helps to assess the significance of Ki67 as prognostic biomarker for MT.

\section{Author Contribution Statement}

All persons who have made substantial contributions to the work participated sufficiently in the intellectual content, conception and design of this work or the analysis and interpretation of the data (when applicable), as well as the writing of the manuscript, their names are listed in the manuscript.

\section{Acknowledgements}

\section{None.}

Ethical Clearance from institutional ethical committee Krishna Institute of Medical Sciences, Deemed to be University, Karad (Ref. No. KIMSDU/IEC/01/2018) was obtained before the start of the study. Ethical clearance certificate has been Uploaded.

\section{Availability of data (if apply to your research)}

The data (patients were) was drawn from outpatient department (OPD) of Oral Medicine and radiology (KIMSDU, Karad) using purposive/subjective sampling technique.

\section{Conflict of interest}

Authors declare that there are no conflicts of interest in this study.

\section{References}

Akhter M, Hossain S, Rahman QB, et al (2011). A study on histological grading of oral squamous cell carcinoma and its co-relationship with regional metastasis. J Oral Maxillofac Pathol, 15, 168-76.

Bathi RJ, Prabhat (2003). P53 aberration in Oral submucous fibrosis and Oral Cancer detected by immunohistochemistry. Indian J Dent Res, 14, 214-9.

Bazarsad S, Zhang X, Kim KY et al (2017). Jayasinghe $\mathrm{RD}$, Tilakaratne WM et al. Identification of a combined biomarker for malignant transformation in oral submucous fibrosis. J Oral Pathol Med, 46, 431-8.

Bhayekar PD, Gaopande VL, Joshi ARet al (2016). Immunohistochemical study of p53, Ki-67, epidermal growth factor receptor, and sexdetermining region Y-box 2 in squamous cell carcinoma of tongue. BLDE Univ J Health Sci, 1, 102-7.

Carreras-Torras C, Gay-Escoda C (2015). Techniques for early diagnosis of oral squamous cell carcinoma: Systematic review. Med Oral Patol Oral Cir Bucal, 20, e305-15.

Dash KC, Mahapatra N, Bhuyan L et al (2020). An immunohistochemical study showing Ki-67 as an analytical marker in oral malignant and premalignant lesions. J Pharm Bioall Sci, 12, S274-8.

Dragomir LP, Simionescu C, Mărgăritescu C (2012). P53, p16 and Ki67 immunoexpression in oral squamous carcinomas. Rom J Morphol Embryol, 53, 89-93.

Dwivedi N, Chandra S, Kashyap B, et al (2013). Suprabasal expression of Ki67 as marker for severity of oral epithelial dysplasia and oral squamous cell carcinoma. Contempo Clin Dent, 4, 7-12.
Hazarey VK, Erlewad DM, Mundhe KA, et al (2007). Oral submucous fibrosis: study of 1000 cases from central India. J Oral Pathol Med, 36, 12-7.

Hsue S, Wang W, Chen C, et al (2007). Malignant transformation in 1458 patients with potentially malignant oral mucosal disorders: a follow-up study based in a Taiwanese hospital. J Oral Path Med, 36, 25-9.

Humayun S, Prasad VR (2011). Expression of p53 protein and Ki67 antigen in oral premalignant lesions and oral squamous cell carcinomas: An immunohistochemical study. Natl $J$ Maxillofac Surg, 2, 38-46.

Iqbal A, Tamgadge S, Tamgadge A et al (2020). Evaluation of Ki-67 expression in oral Submucous fibrosis and its correlation with clinical and histopathological features. $J$ Microsc Ultrastruct, 8, 20-4.

Jayasinghe Rd, Manoja KGD, Gunasinghe MS et al (2015). An analysis of rate and factors affecting malignant transformation of oral submucous fibrosis in patients attending the oral medicine clinic, dental hospital peradeniya, Sri Lanka - a Retrospective study. Sri Lanka J Med, 24, 3-10.

Manjunath S, Himadal CG, Divakar DD, et al (2019). An immunohistochemical study of p53 expressions in oral submucous fibrosis. J Oral Maxillofac Pathol, 23, 308.

Motta Rda R, Zettler CG, Cambruzzi E et al (2009). Ki67 and p53 correlation prognostic value in squamous cell carcinomas of the oral cavity and tongue. Braz J Otorhinolaryngol, 75, 544-49.

Narang RS, Arora A (2017). Oral Submucous fibrosis an overview. Curr Trends Diang Treat, 1, 22-6.

Nair U, Bartsch H, Nair J (2004). Alert for an epidemic of oral cancer due to use of the betel quid substitutes gutkha and pan masala: a review of agents and causative mechanisms. Mutagenesis, 19, 251-62.

Nigam NK, Aravinda K, Dhillon M et al (2014). Prevalence of oral submucous fibrosis among habitual gutkha and areca nut chewers in Moradabad district. J Oral Biology Cranofac Resear, 4, 8-13.

Patel SM, Patel KA, Patel PR, et al (2014). Gupta S. Expression of p53 and Ki-67 in oral dysplasia and squamous cell carcinoma: An immunohistochemical study. Int J Med Sci Public Health, 3, 1201-4.

Raju B, Mehrotra R, Oijordsbakken G et al (2005). Expression of p53, cyclin D1 and Ki-67 in pre-malignant and malignant oral lesions: Association with Clinicopathological Parameters. Anticancer Res, 25, 4699-706.

Ranganathan K, Kavitha R (2011). Proliferation and apoptosis markers in oral submucous fibrosis. J Oral Maxillofac Pathol, 15, 148-53.

Reddy MGS, Gupta A, Kheur S et al (2016). Expression of p53 and ki-67 in oral Squamous cell carcinoma with the background of oral Submucous fibrosis. Int J Curr Resea, 8, 34094-98.

Sharada P, Swaminathan U, Nagamalini BR, et al (2018). A Semi-quantitative analysis of immunohistochemical expression of p63, Ki-67, Cyclin-D1, and p16 in common oral potentially malignant disorders and oral squamous cell carcinoma. J NTR Univ Health Sci, 7, 120-8.

Shih YH, Wang TH, Shieh TM, et al (2019). Oral submucous fibrosis: A Review on Etiopathogenesis, Diagnosis, and Therapy. Int J Mol Sci, 20, 2940.

Shrikrishna BH, Jyothi AC (2016). Prevalence of Areca Nut Eating Habits and its Association with Oral Submucous Fibrosis in Preuniversity Collegegoing Adolescents of Raichur in Karnataka, India: A Prospective Cross-sectional Survey. Int J Head Neck Surg, 7, 197-203.

Sultana N, Pallagatti S, Imam Mohamed A (2011). P53 Expressions in oral submucous fibrosis and oral squamous 
cell carcinoma. Int J Oral Maxillofac Patho, 2, 9-14.

Takkem A, Barakat C, Zakaraia S, et al (2018). Ki-67 prognostic value in different histological grades of oral epithelial dysplasia and oral squamous cell carcinoma. Asian Pac J Cancer Prev, 19, 3279-86.

Utsunomiya H, Tilakaratne WM, Oshiro K, et al (2005). Extracellular matrix remodelling in oral submucous fibrosis: Its stage-specific modes revealed by immunohistochemistry and in situ hybridization. J Oral Pathol Med, 34, 498-507.

Verma R, Singh A, Jaiswal R, et al (2014). Association of Ki67 antigen and p53 protein at invasive tumor front of oral squamous cell carcinoma. Indian J Pathol Microbiol, 57, 553-7.

Vieira FLD, Vieira BJ, Guimaraes MAM et al (2008). Cellular profile of the peritumoral inflammatory infiltrate in squamous cells carcinoma of oral mucosa: Correlation with the expression of Ki67 and histologic grading. BMC Oral Health, 8, 25.

Warnakulasuriya V, Reibel J, Bouquot J, et al (2008). Oral epithelial dysplasia classification systems: predictive value, utility, weaknesses and scope for improvement. J Oral Pathol Med, 37, 127-33.

Wollina U, Verma SB, Ali FM, et al (2015). Oral submucous fibrosis: an update. Clin Cosmetic Invest Dermatol, 8, 193-204.

Yang S, Wang Y, Su N, et al (2018). Changes in prevalence of precancerous oral submucous fibrosis from 1996 to 2013 in Taiwan: A nationwide population-based retrospective study. J Formosan Medi Asso, 117, 147-52.

\section{c) (i) (8)}

This work is licensed under a Creative Commons AttributionNon Commercial 4.0 International License. 